\title{
Review
}

\section{Mitochondria: The Missing Link Between Preconditioning and Neuroprotection}

\author{
Sónia C. Correia ${ }^{\mathrm{a}, \mathrm{b}}$, Renato X. Santos ${ }^{\mathrm{a}, \mathrm{b}}$, George Perry ${ }^{\mathrm{c}, \mathrm{d}}$, Xiongwei Zhu ${ }^{\mathrm{d}}$, Paula I. Moreira ${ }^{\mathrm{a}, \mathrm{e}, *}$ and \\ Mark A. Smith ${ }^{\mathrm{d}, *}$ \\ ${ }^{a}$ Center for Neuroscience and Cell Biology of Coimbra, University of Coimbra, Coimbra, Portugal \\ ${ }^{\mathrm{b}}$ Faculty of Sciences and Technology, Department of Life Sciences, University of Coimbra, Coimbra, Portugal \\ ${ }^{\mathrm{c}}$ UTSA Neurosciences Institute and Department of Biology, University of Texas at San Antonio, San Antonio, TX, \\ USA \\ ${ }^{\mathrm{d}}$ Department of Pathology, Case Western Reserve University, Cleveland, OH, USA \\ ${ }^{\mathrm{e}}$ Faculty of Medicine, Institute of Physiology, University of Coimbra, Coimbra, Portugal
}

Handling Editor: Jesus Avila

Accepted 21 April 2010

\begin{abstract}
The quote "what does not kill you makes you stronger" perfectly describes the preconditioning phenomenon - a paradigm that affords robust brain tolerance in the face of neurodegenerative insults. Over the last few decades, many attempts have been made to identify the molecular mechanisms involved in preconditioning-induced protective responses, and recent data suggests that many of these mechanisms converge on the mitochondria, positing mitochondria as master regulators of preconditioning-triggered endogenous neuroprotection. In this review, we critically discuss evidence for the involvement of mitochondria within the preconditioning paradigm. We will highlight the crucial targets and mediators by which mitochondria are integrated into neuroprotective signaling pathways that underlie preconditioning, putting focus on mitochondrial respiratory chain and mitochondrial reactive oxygen species, mitochondrial ATP-sensitive potassium channels, mitochondrial permeability transition pore, uncoupling proteins, and mitochondrial antioxidant enzyme manganese superoxide dismutase. We also discuss the role of mitochondria in the induction of hypoxia-inducible factor-1, a transcription factor engaged in preconditioning-mediated neuroprotective effects. The identification of intrinsic mitochondrial mechanisms involved in preconditioning will provide new insights which can be translated into potential pharmacological interventions aimed at counteracting neurodegeneration.
\end{abstract}

Keywords: Hypoxia inducible factor-1, mitochondria, neuroprotection, preconditioning, reactive oxygen species

${ }^{*}$ Correspondence to: Mark A. Smith, Ph.D., Department of Pathology, Case Western Reserve University, 2103 Cornell Road, Cleveland, OH 44106, USA. Tel.: +1 216368 3670; Fax: +1 216 368 8964; E-mail: mark.smith@ case.edu. Paula I. Moreira, Ph.D., Center for Neuroscience and Cell Biology, Institute of PhysiologyFaculty of Medicine, University of Coimbra, 3000-354 Coimbra, Portugal. Tel.: +351 239480012; Fax: +351 239480034; E-mail: venta@ci.uc.pt or pismoreira@gmail.com.

\section{INTRODUCTION}

In 1964, the concept of "preconditioning" was introduced to describe the stimulation below the threshold of injury which results in subsequent protection [1]. Almost 20 years later, an adaptation to hypoxia by hypoxia in brain tissue in vitro was reported [2]. More recent research advances validate a protective role for preconditioning in the brain [3-7], and today it is widely accepted that the preconditioning phenomenon re- 
quires small doses of noxious stimulus to afford neuroprotective responses against future injury [8]. Indeed, stimuli such as ischemia, low doses of endotoxin, and hypoxia have all been shown to be able to induce preconditioning-dependent protective responses [9]. The existence of multiple, diverse preconditioning stimuli that confer protection constitute the wellknown phenomenon of "cross-tolerance" [5]. Two distinct forms of preconditioning have been described. Immediate preconditioning occurs within minutes after the preconditioning stimulus and involves cellular changes related to the activity or function of enzymes, secondary messengers, and ion channels. Conversely, delayed preconditioning-induced brain tolerance needs several hours and even days to manifest and is characterized by a dependence on new gene expression and de novo protein synthesis $[5,10,11]$. More recently, it was proposed that preconditioning also elicits stimulus specific genomic reprogramming events, which, in turn, can confer a neuroprotective phenotype [12].

Such monikers aside, the molecular mechanisms responsible for the induction and maintenance of preconditioning-induced brain tolerance are complex and remain largely undefined. That said, mitochondrial-centered mechanisms appear to be important mediators of the preconditioning response [13]. Accumulating data indicates that transient exposure of mitochondria to physiological or pathological stimuli, intracellular events, or pharmacological agents, induces mitochondrial changes that ultimately protect neurons against a variety of lethal insults $[14,15]$. An inter-relationship between mitochondrial function, the preservation of energy metabolism, and a manifestation of the preconditioning-induced neuroprotective effects has been described in in vitro and in vivo models of cerebral ischemia $[14,16]$. Additionally, experimental evidence demonstrates that antioxidants and mitochondrial ATP-sensitive potassium (mitoK ${ }_{A T P}$ ) blockers abolish this preconditioning-induced protection [17, 18], which ascribes a role for mitochondrial reactive oxygen species (ROS) generation and mitoK ${ }_{A T P}$ channel activation in the preconditioning phenomenon.

Mitochondria have been posited to be master integrators of preconditioning-mediated endogenous neuroprotection. Thus, the present review summarizes current knowledge of how mitochondria are involved in preconditioning-induced brain tolerance, putting a focus on mitochondrial respiratory chain and mitochondrial ROS, mitoK $\mathrm{K}_{A T P}$, mitochondrial permeability transition pore (mPTP), uncoupling proteins (UCPs), and mitochondrial antioxidant enzyme manganese su- peroxide dismutase (MnSOD) as specific mitochondrial mediators and targets of preconditioning. Finally, we will highlight the role of mitochondria on the induction of hypoxia-inducible factor-1 (HIF-1), a transcription factor believed to play a critical role in the preconditioning-mediated neuroprotective effects. A better understanding of the mechanisms by which mitochondria are involved in preconditioning will help in the development of novel therapeutic strategies aimed to counteract neurodegeneration.

\section{MITOCHONDRIA, PRECONDITIONING, AND NEUROPROTECTION: MECHANISMS}

Mitochondria are ubiquitous and dynamic organelles responsible for many crucial cellular processes in eukaryotic organisms. In fact, mitochondria are considered the "gatekeepers of life and death". Major functions of mitochondria include the production of over $90 \%$ of cellular ATP, through the TCA cycle and oxidative phosphorylation, the regulation of intracellular calcium $\left(\mathrm{Ca}^{2+}\right)$ and redox signaling, and the arbitration of apoptosis [19-21]. Given the important role of mitochondria in neuronal physiology, it is not surprising that mitochondria actively participate in preconditioning signaling pathways. In the next subsections, we elaborate on specific mitochondrial mediators and targets implicated in the protective responses of preconditioning.

\section{Mitochondrial respiratory chain and reactive oxygen species}

The mitochondrial respiratory chain is one of the primary sources of cellular ROS. Within the four protein complexes associated with the respiratory chain, the primary sites of ROS production and release are complexes I and III [22]. Accumulating data suggests that a slight rise of mitochondrial ROS generation triggers a preconditioning-mediated brain tolerance, suggesting a role for mitochondria in endogenous neuroprotection [23-27]. In fact, preconditioning stimulated by moderate ROS levels protects cultured neurons against different damaging agents and against subsequent massive oxygen radical formation [24]. To this end, an immediate and constant radical scavenger abolishes such ROS-induced neuronal preconditioning [25]. Also, preconditioning with low concentrations of hydrogen peroxide $\left(\mathrm{H}_{2} \mathrm{O}_{2}\right)$ protects $\mathrm{PC} 12$ cells against apoptosis induced by subsequent lethal oxidative stress [28]. 
The mechanisms behind $\mathrm{H}_{2} \mathrm{O}_{2}$-induced neuroprotective effects include attenuation of mitochondrial membrane potential $(\Delta \Psi \mathrm{m})$ loss, increase in ROS generation, and overexpression of Bcl-2 [29]. Accordingly, it was demonstrated that the generation of $\mathrm{H}_{2} \mathrm{O}_{2}$ during brief oxygen-glucose deprivation (OGD) is the main trigger involved in the mechanism of preconditioninginduced neuronal protection [30]. More recently, a preconditioning effect was reported following in situ administration of $\mathrm{H}_{2} \mathrm{O}_{2}$ inside the brain cortex which directly implicates ROS during the triggering phase of cerebral preconditioning [31]. A relationship between mitoK $\mathrm{K}_{A T P}$ channels and ROS has been postulated, since the protection induced by $\mathrm{H}_{2} \mathrm{O}_{2}$ against cerebral ischemia-reperfusion injury was blocked by a mitoK ${ }_{A T P}$ channels antagonist, and the antioxidant $\mathrm{N}$-acetyl-cysteine (NAC) blocked protection induced by diazoxide, a mitoK $\mathrm{K}_{A T P}$ channels opener [31]. This strong and direct relationship between ROS and mitoK $_{A T P}$ further confirms a central stage for mitochondria in the neuroprotection induced by cerebral preconditioning [31].

The inhibition of succinate dehydrogenase (SDH) by 3-nitropropionic acid (3-NPA), an agent known to increase the production of ROS probably at mitochondrial complex I, was shown to promote tolerance to focal cerebral ischemia [32], implicating mitochondrial ROS in cerebral preconditioning. 3-NPA was also able to induce delayed preconditioning in rats when administered 3 days after transient middle cerebral artery occlusion (MCAO) by reducing infarct volume by about $20 \%$ [33]. The compound NS1619, which inhibits complex I of the mitochondrial respiratory chain, also induces neuronal preconditioning by increasing ROS production and mitochondrial depolarization [34,35], whereas ROS scavengers during the preconditioning phase significantly abrogates these neuroprotective effects [34]. Furthermore, immediate NS1619 preconditioning decreases $\mathrm{Ca}^{2+}$ influx through glutamate receptors, increases superoxide dismutase (SOD) activity, reduces ROS response during glutamate stimulation, and preserves ATP levels [34]. Finally, it has been proposed that "minor" mitochondrial ROS generation induces fission and fusion of mitochondria and relocates the mitochondrial network to form a "mitochondriafree" gap, which may play a role in mitochondrial ROSmediated protective "preconditioning" by preventing the propagation of ROS during oxidative insult.

Overall these findings point to a critical role for mitochondria and mitochondrial ROS in neuroprotective mechanisms triggered by preconditioning.

\section{Mitochondrial ATP-sensitive potassium channels}

There is an ongoing debate concerning the role of mitoK $\mathrm{K}_{A T P}$ channels in the preconditioning phenomenon of the brain [13]. These channels are localized in the inner mitochondrial membrane and regulate mitochondrial function in several tissues, including the brain [36-38]. Brain mitochondria contain seven times more mitoK ${ }_{A T P}$ channels than liver or heart mitochondria, which reflect the importance of these channels in neuronal functionality and integrity [36]. Recent findings suggest a key role for the mitoK $\mathrm{K}_{A T P}$ channels as both triggers and end effectors in acute and delayed neuroprotection by preconditioning [13, 23]. Indeed, activation of mitoK $\mathrm{K}_{A T P}$ channels with pharmacological agents mimics the preconditioningassociated protective effects $[39,40]$. Conversely, physiological or chemical preconditioning is abrogated by mitoK $_{A T P}$ channels blockers, such as glibenclamide and 5-hydroxydecanoate (5-HD) [40]. Some progress has been made to elucidate the mechanisms underlying the role of mitoK $\mathrm{K}_{A T P}$ channels in preconditioning protection. For example, opening mitoK ${ }_{A T P}$ channels may decrease $\Delta \Psi \mathrm{m}$, promoting an increase in the electron transport chain rate, and, consequently, increasing ATP production [41]. In addition, the activation of mitoK $_{A T P}$ channels was reported to induce neuronal protection by attenuating mitochondrial $\mathrm{Ca}^{2+}$ overload and, thus, preventing mPTP induction. More recently, the signal transduction pathways initiated by epsilon protein kinase $\mathrm{C}(\varepsilon \mathrm{PKC})$ were shown to mediate preconditioning-induced neuroprotection through the activation of mitoK ${ }_{A T P}$ channels [42]. Further, abolishment of these beneficial effects of preconditioning was observed following inhibition of both mitoK $\mathrm{K}_{A T P}$ channels or $\varepsilon \mathrm{PKC}$ [42].

Diazoxide, a selective mitoK $\mathrm{K}_{A T P}$ channels opener, has been suggested to induce mild oxidative stress and preconditioning-like neuroprotection [43]. However, at high doses diazoxide also inhibits SDH, the complex II of the mitochondrial respiratory chain, leading to the release of ROS in a mitoK ${ }_{A T P}$ channelindependent manner [44]. In a recent review, it was proposed that diazoxide is the most potent inducer of preconditioning-mediated protection due to the combined effects of mitochondrial membrane depolarization and enhanced ROS production through SDH inhibition [13]. The immediate preconditioning induced by low doses of diazoxide was shown to preserve neuronal and vascular function after cerebral ischemia [45]. Additionally, this immediate preconditioning with dia- 
zoxide protects against ischemia-reperfusion injury by preventing mitochondrial swelling and $\mathrm{Ca}^{2+}$ accumulation in brain cells [46]. Diazoxide also induces delayed preconditioning in neurons via the acute generation of superoxide anion $\left(\mathrm{O}_{2}^{-}\right)$and activation of protein kinases protecting against the oxidative stress induced by OGD, a well-established in vitro model of cerebral ischemia-reperfusion [44]. It was also demonstrated that diazoxide protects neurons against ischemiainduced death by increasing mitochondrial Bcl-2 levels and suppressing the translocation of Bax to the mitochondria and by preventing subsequent cytochrome c release, suggesting that mitoK $\mathrm{K}_{A T P}$ channel activation may stabilize mitochondrial function by differentially modulating pro-apoptotic and anti-apoptotic proteins [47]. Some in vivo studies have also revealed that the acute and delayed preconditioning with diazoxide has a neuroprotective effect against transient focal cerebral ischemia $[48,49]$. Moreover, diazoxide is effective in protecting hippocampal neurons against oxidative injury induced by exposure to ferrous sulfate $\left(\mathrm{FeSO}_{4}\right)$ and amyloid- $\beta(\mathrm{A} \beta)$, leading to a suppression of intracellular peroxide formation [50]. Similarly, diazoxide exerts a protective effect against $\mathrm{A} \beta$-induced cytotoxicity in endothelial cells [51] and neurons by suppressing $\mathrm{A} \beta$-mediated increases in $\Delta \Psi \mathrm{m}$ and intracellular ROS levels [52]. $\mathrm{A} \beta_{1-42}$ also enhances the expression of $\mathrm{K}_{A T P}$ channel subunits in cholinergic neurons, suggesting that the change in the composition of $\mathrm{K}_{A T P}$ channels may contribute to the dysfunction of $\mathrm{K}_{A T P}$ channels and disturbances in membrane excitability [53]. Of note, pretreatment with diazoxide reverses the $\mathrm{A} \beta_{1-42}$-induced enhancement in the expression of $\mathrm{K}_{A T P}$ channels subunits [53]. In an in vitro model of Parkinson's disease (PD), diazoxide protects neurons against $\mathrm{MPP}^{+}$-induced cytotoxicity via inhibition of ROS overproduction, which improves mitochondrial function [54]. Similarly, this mitoK $_{A T P}$ opener improves both parkinsonian symptoms and neurochemical alterations in rats treated with rotenone, a model of PD [55]. These results suggest that mitoK $\mathrm{K}_{A T P}$ activation could provide a new therapeutic strategy for the treatment of early PD. 5-HD abolishes all neurorestorative effects of diazoxide [55], which is consistent with previous studies showing that the activation of mitoK $\mathrm{K}_{A T P}$ channels with diazoxide in PC12 cells induces protection against the neurotoxic effects of rotenone but that this protection being attenuated by 5-HD [56,57]. In vitro, diazoxide prevents rotenone-induced microglial activation and the subsequent production of pro-inflammatory factors, such as tumor necrosis factor alpha (TNF- $\alpha$ ) and inducible isoform of nitric oxide synthase (iNOS) [58].

BMS-191095, a selective mitoK ${ }_{A T P}$ channels opener, has been shown to induce both immediate and delayed preconditioning in neurons via mechanisms that involve mitochondrial depolarization and PKC activation which attenuate free radical production during neuronal stress [59]. In addition, BMS-191095 depolarizes mitochondria without ROS generation, activates the phosphoinositide 3-kinase (PI3-K) signaling pathway, and increases ATP content and catalase expression; such mechanisms undoubtedly contribute to the neuroprotective effects afforded by this mitoK ${ }_{A T P}$ channels opener [60]. In a similar vein, BMS-191095 affords protection against cerebral ischemia by delayed preconditioning via selective opening of mitoK $\mathrm{K}_{A T P}$ channels without ROS generation [61].

In summary, the activation of mitoK ${ }_{A T P}$ channels seems to be a key event that elicits neuroprotection by preconditioning and, as such, these channels represent promising therapeutic targets to counteract neurodegeneration.

\section{Mitochondrial permeability transition pore}

As already mentioned, mitochondria have a high capacity for $\mathrm{Ca}^{2+}$ sequestration, contributing to normal neuronal function [62-64]. Conversely, mitochondrial $\mathrm{Ca}^{2+}$ overload leads to the induction of the MPTP, resulting in osmotic swelling and a collapse of the outer mitochondrial membrane. The mPTP, a dynamic multiprotein complex located at the contact site between the mitochondrial inner and outer membranes, is comprised of the voltage-dependent anion channel, the adenine nucleotide translocator, and the regulatory protein cyclophilin D (CypD). Once open, the mPTP allows the release of pro-apoptotic proteins, including cytochrome $c$ and apoptosis-inducing factor, from the mitochondrial intermembrane space into the cytoplasm. Consequently, released cytochrome $c$ binds apoptotic protease-activating factor 1 and activates the caspase cascade [65-67]. While it is unclear whether bona fide apoptosis occurs during neurodegeneration [68-70], it is clear that the mPTP is an important inducer of cell death. For instance, mPTP induction has been proposed to be integral to the apoptotic mechanism implicated in ischemia-triggered mitochondrial dysfunction and neuronal cell death [71-74], such that cyclosporine A, which inhibits mPTP, has neuroprotective effects against ischemia-induced brain injury [75,76]. Accordingly, CypD-knockout mice also display a dramatic re- 
duction in the size of brain infarcts [77]. Additionally, increased susceptibility to $\mathrm{mPTP}$ induction is promoted by $\mathrm{A} \beta$ peptides, suggesting an involvement of the mPTP in AD pathophysiology [78,79]. Consistent with this, CypD deficiency substantially improves learning and memory and synaptic function in an AD mouse model and alleviates $\mathrm{A} \beta$-mediated reductions in longterm potentiation [80]. Also, in PD, mPTP may play a role, such that the overexpression of $\alpha$-synuclein in cell culture and in transgenic mice impairs mitochondrial function and increases susceptibility to MPTP induction $[81,82]$.

Compelling evidence indicates that the inhibition of mPTP opening and its signaling cascade represent crucial events responsible for preconditioning-mediated cytoprotection in both heart and brain [23,83-85]. Despite the fact that the molecular mechanisms underlying these effects are still the objects of investigation, nitrite $\left(\mathrm{NO}_{2}^{-}\right)$, a known endogenous mediator of preconditioning as well as protein kinases, has been proposed as a possible regulator of the $\mathrm{MPTP}[86,87]$. Alternately, a reduction of the oxidation of critical thiol groups of the MPTP, which sensitize pore opening to $\mathrm{Ca}^{2+}$, could represent another potential mechanism involved in preconditioning-mediated inhibition of $\mathrm{MPTP}$ opening [85]. When compared with heart, less is known about the functional role of mPTP for preconditioning in the brain. This said, activation of mitoK $\mathrm{K}_{A T P}$ channels protects the brain against injury through the attenuation of mitochondrial $\mathrm{Ca}^{2+}$ overload and, thus, prevents $\mathrm{mPTP}$ induction [88]. A signaling pathway linking mitoK $\mathrm{K}_{A T P}$ and $\mathrm{mPTP}$ has been proposed where increased $\mathrm{K}^{+}$conductance after mitoK ${ }_{A T P}$ opening alkalinizes the mitochondrial matrix and increases the generation of $\mathrm{H}_{2} \mathrm{O}_{2}$, which in turn activates an mPTPassociated $\mathrm{PKC} \varepsilon$. In addition, a pivotal role for $\mathrm{PKC} \varepsilon$ in the induction of tolerance after ischemic preconditioning has been shown in experimental models of cerebral ischemia [89]. Indeed, ischemic preconditioning has been shown to promote a significant increase in respiration and the phosphorylation of respiratory proteins via $\mathrm{PKC} \varepsilon$ in mitochondria located in synaptosomes [90]. Furthermore, it has been shown that preconditioned neurons with short periods of OGD contain large mitochondria with dense matrices, increased respiration and an elevated $\mathrm{Ca}^{2+}$ loading capacity [91]. Further, a recent study demonstrated that mitochondrial hyperpolarization following short periods of OGD increased the $\mathrm{Ca}^{2+}$ buffering capacity of mitochondria in hippocampal neurons suggesting that enhanced buffering capacity of the mitochondria may be linked to preconditioning after short-term ischemic episodes [91]. Therefore, MPTP is critically involved in preconditioning-induced brain tolerance.

\section{Mitochondrial uncoupling proteins}

In the brain, as well as in the heart, preconditioning is related to a moderate uncoupling of the mitochondrial respiratory chain $[23,92]$. Uncoupling proteins (UCPs) are located in the inner mitochondrial membrane and dissipate the electrochemical proton gradient between the intermembrane space and the mitochondrial matrix to uncouple electron transport from ATP synthesis. As such, UCPs play a critical role in energy balance [93]. One of these proteins, UCP2, expressed in the brain, predominantly in neurons, has been proposed to contribute to neuroprotection by reducing mitochondrial ROS generation [94,95]. Indeed, Mattiasson and colleagues [96] provided evidence of increased expression of brain UCP2, measured as mRNA by in situ hybridization, after preconditioning ischemia in $v i$ vo. It was found that UCP2 prevents neuronal death and diminishes brain dysfunction after stroke and brain trauma, suggesting that UCP2 is an inducible protein that is neuroprotective by activating cellular redox signaling or by inducing mild mitochondrial uncoupling that prevents the release of apoptogenic proteins [96]. Accordingly, in vitro and in vivo experiments show that upregulation of UCP2 is part of a neuroprotective set of responses to various cellular stresses involved in preconditioning and protection against free radicalinduced cell death is observed in PC12 cells transfected with UCP2 [97]. Moreover, in transgenic mice that expressed UCP2 constitutively in the hippocampus before seizure induction, a robust reduction in cell death was observed. Since UCP2 increases mitochondrial number and ATP levels with a parallel decrease in free radical-induced damage, the authors proposed that mitochondrial UCPs precondition neurons by dissociating cellular energy production from that of free radicals to withstand the harmful effects of cellular stress occurring in a variety of neurodegenerative disorders [97]. More recently, it was confirmed that ischemic preconditioning causes increased expression of UCP2 protein in vivo, the timing of which is appropriate for protection against ischemia/reperfusion injury in the hippocampus [98]. In addition, this increase in UCP2 immunoreactivity in preconditioned brains was blocked by ROS scavenging, which demonstrate a dependence of UCP2 expression on ROS production. This finding is in agreement with previous studies that demonstrat- 

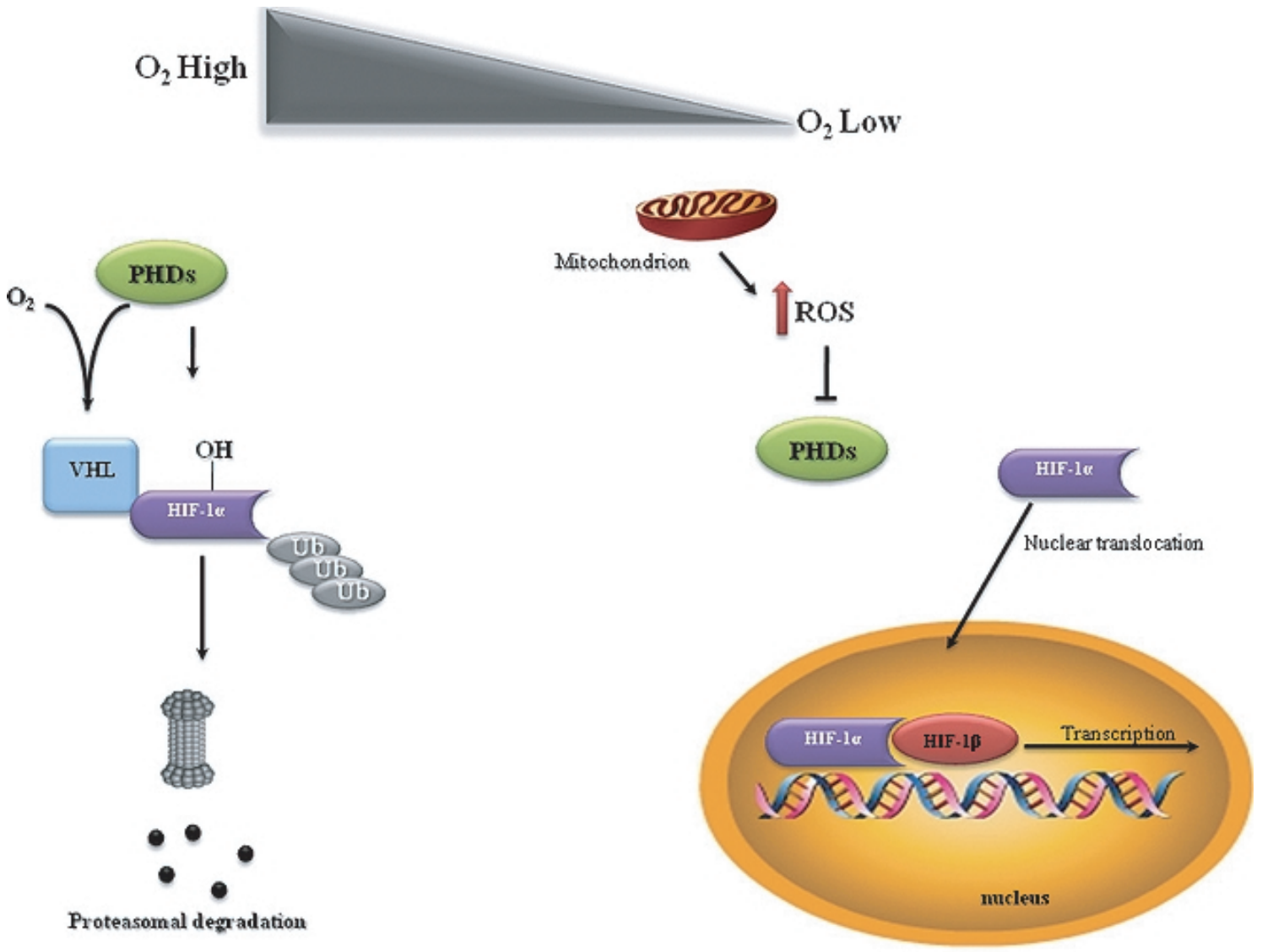

Fig. 1. Schematic illustration of the involvement of mitochondrial reactive oxygen species (ROS) in hypoxia-inducible factor 1 (HIF-1) stabilization. HIF-1 is a heterodimeric protein composed of a constitutively expressed HIF-1 $\beta$ subunit and an inducible HIF- $1 \alpha$ subunit. In the presence of molecular oxygen $\left(\mathrm{O}_{2}\right)$, HIF-1 $\alpha$ is hydroxylated by prolyl hydroxylase enzymes (PHDs) and rapidly degraded by ubiquitin-proteasome system. Under hypoxic conditions, the generation of ROS by the mitochondrial respiratory chain inhibits PHDs activity, preventing the hydroxylation of HIF- $1 \alpha$, resulting in HIF- $1 \alpha$ stabilization and translocation to the nucleus. Consequently, HIF- $1 \alpha$ dimerizes with HIF- $1 \beta$, initiating the transcription of HIF-1-responsiveness genes.

ed that excess ROS production can induce UCP2 overexpression and activation [93,99,100]. Finally, it was shown that both resveratrol and ischemic preconditioning induce neuroprotection against cerebral ischemic damage through alterations in mitochondrial function via the sirtuin1 (SIRT1)-UCP2 pathway [101].

\section{Manganese superoxide dismutase}

The brain is especially prone to oxidative stressinduced damage due to its high levels of polyunsaturated fatty acids, high oxygen consumption, high content in transition metals, and poor antioxidant defenses [102]. To protect the mitochondria from $\mathrm{O}_{2}^{-}$mediated oxidative damage, cells express a nuclearencoded mitochondrial enzyme, MnSOD, that scavenges $\mathrm{O}_{2}^{-}$generated by the electron-transport chain in the mitochondria [103]. Indeed, previous reports demonstrated that overexpression of MnSOD protects mice against focal cerebral ischemia [104,105]. More recently, Scorziello and collaborators [106] proposed that MnSOD may represent the crucial step through which the NO/Ras/ERK1/2 pathway promotes neuroprotection during preconditioning.

\section{MITOCHONDRIA AND HIF-1: GOOD PARTNERS?}

A number of key molecules and signaling pathways have been proposed to participate in preconditioning. The induction of the hypoxia signaling pathway with the concomitant stabilization and transcriptional activation of the transcription factor HIF-1 has emerged 
as one of the major cellular pathways responsible for preconditioning-induced neuroprotection. HIF-1 is a heterodimeric protein composed of a constitutively expressed HIF- $1 \beta$ subunit and an inducible HIF- $1 \alpha$ subunit. Under normoxic conditions, HIF- $1 \alpha$ is hydroxylated by prolyl hydroxylase enzymes (PHDs) and rapidly degraded by the ubiquitin-proteasome system (Fig. 1). On the other hand, during hypoxic conditions, enzymatic inhibition of PHDs abrogates HIF-1 $\alpha$ proteasomal degradation and results in HIF- $1 \alpha$ stabilization and translocation to the nucleus. In the nucleus, HIF- $1 \alpha$ recruits HIF- $1 \beta$ and modulates the expression of a wide range of genes involved in angiogenesis, metabolism, apoptosis, and cell survival [107]. HIF1 induction has been shown to afford neuroprotection in cerebral ischemic stroke and chronic neurodegenerative disorders, such as AD and PD [107]. Indeed, in a neuronal-specific HIF-1 $\alpha$ knockout study aimed to evaluate the significance of HIF- $1 \alpha$ in the ischemic brain, it was found that loss of HIF-1 increased the extent of brain damage in mice subjected to MCAO and reduced survival rate [108]. Conversely, pharmacologic HIF-1 activators 3,4-dihydroxybenzoic acid, deferoxamine (DFO), and 2,2-dipyridyl significantly reduced ischemic injury in wild-type mice, whereas the effectiveness of these compounds was significantly attenuated in mice with neuron-specific HIF$1 \alpha$ knockdown [108]. Additionally, activation of HIF1 by the overexpression of a non-degradable HIF-1 $\alpha$ was also shown to prevent $\mathrm{A} \beta_{1-42}$-induced neurotoxicity, suggesting a neuroprotective role of HIF-1 in AD [109]. Recently, it was reported that in in vitro and in vivo models of $\mathrm{PD}, 3$,4-dihydroxybenzoate protects against 1-methyl-4-phenyl-1,2,3,6-tetrahydropyridine (MPTP)-induced neurotoxicity possibly through the induction of HIF- $1 \alpha$ [110].

HIF-1 $\alpha$ activation seems to be strictly linked to mitochondrial function. Indeed, under hypoxic conditions, mitochondria act as oxygen sensors and convey signals to HIF-1, with mitochondrial ROS being the putative signaling molecules between a cellular $\mathrm{O}_{2}$-sensor and HIF-1. ROS generated by the $\mathrm{Q}_{0}$ site of complex III have been documented to be critical in the hypoxiamediated survival signaling [111]. Consistent with this, previous studies reported that mitochondrial ROS generation prevent the hydroxylation of HIF- $1 \alpha$, stabilizing HIF- $1 \alpha$ and promoting its translocation to the nucleus and dimerization with HIF- $1 \beta$, initiating the transcription of target genes (Fig. 1) [111-113]. Conversely, mitochondrial DNA-depleted $\left(\rho^{0}\right)$ cells, without a functional mitochondrial respiratory chain, failed to in- crease ROS generation and HIF-1 $\alpha$ accumulation under hypoxic conditions [114,115]. Exogenous application of $\mathrm{H}_{2} \mathrm{O}_{2}$ has been also shown to induce HIF-1 $\alpha$ under normoxic conditions, whereas ROS scavengers block the hypoxic induction of HIF, which further confirms the involvement of ROS in HIF-1 induction [113, 116]. Additionally, in $\rho^{0}$ cells, exposure to low levels of $\mathrm{H}_{2} \mathrm{O}_{2}$ stabilizes HIF- $1 \alpha$ protein during normoxia and increases hypoxia responsive element (HRE)luciferase [115].

A crosstalk between mitochondrial ROS and HIF1 has been proposed to underlie preconditioningmediated protective events [107]. Indeed, evidence from the literature demonstrates that hypoxic preconditioning-induced neuroprotection is associated with ROS production and subsequent induction of HIF- 1 and its downstream gene erythropoietin [117]. Confirming this, low levels of exogenous $\mathrm{H}_{2} \mathrm{O}_{2}$ increase HIF$1 \alpha$ expression and protect against ischemia in primary cortical neurons [118].

Overall, these findings provide evidence for the action of mitochondrial ROS on HIF- $1 \alpha$ stabilization and activity, a transcriptional regulator of preconditioningmediated neuroprotective events.

\section{FINAL REMARKS}

The experimental data summarized in this review suggest a pivotal role for mitochondria in neuroprotective events provided by preconditioning. Strong evidence demonstrates that the mitochondrial respiratory chain and mitochondrial ROS, mitoK ${ }_{A T P}$, mPTP, UCP2, and mitochondrial antioxidant enzyme MnSOD, are all targets and mediators involved in preconditioning-induced neuroprotective responses. Indeed, "mitochondrial preconditioning" has many neuroprotective effects, both during and following neurotoxic insults, including an improvement of neuronal viability, the attenuation of the intracellular $\mathrm{Ca}^{2+}$ influx, suppression of ROS generation, the inhibition of apoptosis, and the maintenance of ATP levels.

Understanding the precise mitochondrial mechanisms involved in preconditioning will provide important information necessary to develop new and more effective therapeutic strategies for neurodegeneration.

\section{ACKNOWLEDGMENTS}

Work in the authors' laboratories is supported by the National Institutes of Health (AG024028 and AG031852) and the Alzheimer's Association. 
Authors' disclosures available online (http://www.jalz.com/disclosures/view.php?id=434).

\section{REFERENCES}

[1] Janoff A (1964) Alterations in lysosomes (intracellular enzymes) during shock; effects of preconditioning (tolerance) and protective drugs. Int Anesthesiol Clin 2, 251-269.

[2] Schurr A, Reid KH, Tseng MT, West C, Rigor BM (1986) Adaptation of adult brain tissue to anoxia and hypoxia in vitro. Brain Res 374, 244-248.

[3] Kitagawa K, Matsumoto M, Kuwabara K, Tagaya M, Ohtsuki T, Hata R, Ueda H, Handa N, Kimura K, Kamada T (1991) 'Ischemic tolerance' phenomenon detected in various brain regions. Brain Res 561, 203-211.

[4] Dawson VL, Dawson TM (2000) Neuronal ischaemic preconditioning. Trends Pharmacol Sci 21, 423-424.

[5] Kirino T (2002) Ischemic tolerance. J Cereb Blood Flow Metab 22, 1283-1296.

[6] Schaller B, Graf R (2002) Cerebral ischemic preconditioning An experimental phenomenon or a clinical important entity of stroke prevention? J Neurol 249, 1503-1511.

[7] Meller R, Minami M, Cameron JA, Impey S, Chen D, Lan JQ, Henshall DC, Simon RP (2005) CREB-mediated Bcl-2 protein expression after ischemic preconditioning. J Cereb Blood Flow Metab 25, 234-246.

[8] Dirnagl U, Simon RP, Hallenbeck JM (2003) Ischemic tolerance and endogenous neuroprotection. Trends Neurosci 26, 248-254.

[9] Cadet JL, Krasnova IN (2009) Cellular and molecular neurobiology of brain preconditioning. Mol Neurobiol 39, 50-61.

[10] Gidday JM (2006) Cerebral preconditioning and ischaemic tolerance. Nat Rev Neurosci 7, 437-448.

[11] Barone FC, White RF, Spera PA, Ellison J, Currie RW, Wang X, Feuerstein GZ (1998) Ischemic preconditioning and brain tolerance: temporal histological and functional outcomes, protein synthesis requirement, and interleukin-1 receptor antagonist and early gene expression. Stroke 29, 1937-1950; discussion 1950-1931.

[12] Stenzel-Poore MP, Stevens SL, King JS, Simon RP (2007) Preconditioning reprograms the response to ischemic injury and primes the emergence of unique endogenous neuroprotective phenotypes: a speculative synthesis. Stroke 38, 680685.

[13] Busija DW, Gaspar T, Domoki F, Katakam PV, Bari F (2008) Mitochondrial-mediated suppression of ROS production upon exposure of neurons to lethal stress: mitochondrial targeted preconditioning. Adv Drug Deliv Rev 60, 1471-1477.

[14] Perez-Pinzon MA, Dave KR, Raval AP (2005) Role of reactive oxygen species and protein kinase $\mathrm{C}$ in ischemic tolerance in the brain. Antioxid Redox Signal 7, 1150-1157.

[15] Duchen MR (2004) Roles of mitochondria in health and disease. Diabetes 53(Suppl 1), S96-102.

[16] Dave KR, Saul I, Prado R, Busto R, Perez-Pinzon MA (2006) Remote organ ischemic preconditioning protect brain from ischemic damage following asphyxial cardiac arrest. $\mathrm{Neu}$ rosci Lett 404, 170-175.

[17] Oldenburg O, Cohen MV, Yellon DM, Downey JM (2002) Mitochondrial K(ATP) channels: role in cardioprotection. Cardiovasc Res 55, 429-437.

[18] Vanden Hoek TL, Becker LB, Shao Z, Li C, Schumacker PT (1998) Reactive oxygen species released from mitochondria during brief hypoxia induce preconditioning in cardiomyocytes. J Biol Chem 273, 18092-18098.

[19] Beal MF (2005) Mitochondria take center stage in aging and neurodegeneration. Ann Neurol 58, 495-505.

[20] Mattson MP, Gleichmann M, Cheng A (2008) Mitochondria in neuroplasticity and neurological disorders. Neuron $\mathbf{6 0}$, 748-766.

[21] Green DR, Kroemer G (2004) The pathophysiology of mitochondrial cell death. Science 305, 626-629.

[22] Zhang DX, Gutterman DD (2007) Mitochondrial reactive oxygen species-mediated signaling in endothelial cells. Am J Physiol Heart Circ Physiol 292, H2023-2031.

[23] Dirnagl U, Meisel A (2008) Endogenous neuroprotection: mitochondria as gateways to cerebral preconditioning? $\mathrm{Neu}$ ropharmacology 55, 334-344.

[24] Ravati A, Ahlemeyer B, Becker A, Klumpp S, Krieglstein J (2001) Preconditioning-induced neuroprotection is mediated by reactive oxygen species and activation of the transcription factor nuclear factor-kappaB. J Neurochem 78, 909-919.

[25] Ravati A, Ahlemeyer B, Becker A, Krieglstein J (2000) Preconditioning-induced neuroprotection is mediated by reactive oxygen species. Brain Res 866, 23-32.

[26] Jou MJ (2008) Pathophysiological and pharmacological implications of mitochondria-targeted reactive oxygen species generation in astrocytes. Adv Drug Deliv Rev 60, 1512-1526.

[27] Dirnagl U, Becker K, Meisel A (2009) Preconditioning and tolerance against cerebral ischaemia: from experimental strategies to clinical use. Lancet Neurol 8, 398-412.

[28] Tang XQ, Chen J, Tang EH, Feng JQ, Chen PX (2005) Hydrogen peroxide preconditioning protects $\mathrm{PC} 12$ cells against apoptosis induced by oxidative stress. Sheng Li Xue Bao 57 , 211-216.

[29] Tang XQ, Feng JQ, Chen J, Chen PX, Zhi JL, Cui Y, Guo RX, Yu HM (2005) Protection of oxidative preconditioning against apoptosis induced by $\mathrm{H} 2 \mathrm{O} 2$ in $\mathrm{PC} 12$ cells: mechanisms via MMP, ROS, and Bcl-2. Brain Res 1057, 57-64.

[30] Furuichi T, Liu W, Shi H, Miyake M, Liu KJ (2005) Generation of hydrogen peroxide during brief oxygen-glucose deprivation induces preconditioning neuronal protection in primary cultured neurons. J Neurosci Res 79, 816-824.

[31] Simerabet M, Robin E, Aristi I, Adamczyk S, Tavernier B, Vallet B, Bordet R, Lebuffe G (2008) Preconditioning by an in situ administration of hydrogen peroxide: involvement of reactive oxygen species and mitochondrial ATP-dependent potassium channel in a cerebral ischemia-reperfusion model. Brain Res 1240, 177-184.

[32] Wiegand F, Liao W, Busch C, Castell S, Knapp F, Lindauer U, Megow D, Meisel A, Redetzky A, Ruscher K, Trendelenburg G, Victorov I, Riepe M, Diener HC, Dirnagl U (1999) Respiratory chain inhibition induces tolerance to focal cerebral ischemia. J Cereb Blood Flow Metab 19, 1229-1237.

[33] Horiguchi T, Kis B, Rajapakse N, Shimizu K, Busija DW (2003) Opening of mitochondrial ATP-sensitive potassium channels is a trigger of 3-nitropropionic acid-induced tolerance to transient focal cerebral ischemia in rats. Stroke 34, 1015-1020.

[34] Gaspar T, Domoki F, Lenti L, Katakam PV, Snipes JA, Bari F, Busija DW (2009) Immediate neuronal preconditioning by NS1619. Brain Res 1285, 196-207.

[35] Gaspar T, Snipes JA, Busija AR, Kis B, Domoki F, Bari F, Busija DW (2008) ROS-independent preconditioning in neurons via activation of mitoK(ATP) channels by BMS191095. J Cereb Blood Flow Metab 28, 1090-1103.

[36] Bajgar R, Seetharaman S, Kowaltowski AJ, Garlid KD, Pau- 
cek P (2001) Identification and properties of a novel intracellular (mitochondrial) ATP-sensitive potassium channel in brain. J Biol Chem 276, 33369-33374.

[37] Debska G, May R, Kicinska A, Szewczyk A, Elger CE, Kunz WS (2001) Potassium channel openers depolarize hippocampal mitochondria. Brain Res 892, 42-50.

[38] Kulawiak B, Bednarczyk P (2005) Reconstitution of brain mitochondria inner membrane into planar lipid bilayer. Acta Neurobiol Exp (Wars) 65, 271-276.

[39] Garlid KD, Paucek P, Yarov-Yarovoy V, Murray HN, Darbenzio RB, D'Alonzo AJ, Lodge NJ, Smith MA, Grover GJ (1997) Cardioprotective effect of diazoxide and its interaction with mitochondrial ATP-sensitive $\mathrm{K}+$ channels. Possible mechanism of cardioprotection. Circ Res 81, 1072-1082.

[40] Szewczyk A, Wojtczak L (2002) Mitochondria as a pharmacological target. Pharmacol Rev 54, 101-127.

[41] Inoue I, Nagase H, Kishi K, Higuti T (1991) ATP-sensitive $\mathrm{K}+$ channel in the mitochondrial inner membrane. Nature 352, 244-247.

[42] Raval AP, Dave KR, DeFazio RA, Perez-Pinzon MA (2007) epsilonPKC phosphorylates the mitochondrial $\mathrm{K}(+)$ (ATP) channel during induction of ischemic preconditioning in the rat hippocampus. Brain Res 1184, 345-353.

[43] Samavati L, Monick MM, Sanlioglu S, Buettner GR, Oberley LW, Hunninghake GW (2002) Mitochondrial K(ATP) channel openers activate the ERK kinase by an oxidant-dependent mechanism. Am J Physiol Cell Physiol 283, C273-281.

[44] Kis B, Rajapakse NC, Snipes JA, Nagy K, Horiguchi T, Busija DW (2003) Diazoxide induces delayed pre-conditioning in cultured rat cortical neurons. J Neurochem 87, 969-980.

[45] Domoki F, Perciaccante JV, Veltkamp R, Bari F, Busija DW (1999) Mitochondrial potassium channel opener diazoxide preserves neuronal-vascular function after cerebral ischemia in newborn pigs. Stroke 30, 2713-2718; discussion 27182719.

[46] Domoki F, Bari F, Nagy K, Busija DW, Siklos L (2004) Diazoxide prevents mitochondrial swelling and $\mathrm{Ca} 2+$ accumulation in CA1 pyramidal cells after cerebral ischemia in newborn pigs. Brain Res 1019, 97-104.

[47] Liu D, Lu C, Wan R, Auyeung WW, Mattson MP (2002) Activation of mitochondrial ATP-dependent potassium channels protects neurons against ischemia-induced death by a mechanism involving suppression of Bax translocation and cytochrome c release. J Cereb Blood Flow Metab 22, 431443.

[48] Mayanagi K, Gaspar T, Katakam PV, Busija DW (2007) Systemic administration of diazoxide induces delayed preconditioning against transient focal cerebral ischemia in rats. Brain Res 1168, 106-111.

[49] Shimizu K, Lacza Z, Rajapakse N, Horiguchi T, Snipes J, Busija DW (2002) MitoK(ATP) opener, diazoxide, reduces neuronal damage after middle cerebral artery occlusion in the rat. Am J Physiol Heart Circ Physiol 283, H1005-1011.

[50] Goodman Y, Mattson MP (1996) K+ channel openers protect hippocampal neurons against oxidative injury and amyloid beta-peptide toxicity. Brain Res 706, 328-332.

[51] Chi X, Sutton ET, Hellermann G, Price JM (2000) Potassium channel openers prevent beta-amyloid toxicity in bovine vascular endothelial cells. Neurosci Lett 290, 9-12.

[52] Ma G, Chen S (2004) Diazoxide and N omega-nitro-Larginine counteracted A beta 1-42-induced cytotoxicity. Neuroreport 15, 1813-1817.

[53] Ma G, Gao J, Fu Q, Jiang L, Wang R, Zhang Y, Liu K (2009) Diazoxide reverses the enhanced expression of K(ATP) sub- units in cholinergic neurons caused by exposure to $\mathrm{A} \beta(1-42)$. Neurochem Res 34, 2133-2140.

[54] Xie J, Duan L, Qian X, Huang X, Ding J, Hu G (2010) $\mathrm{K}$ (ATP) channel openers protect mesencephalic neurons against MPP+-induced cytotoxicity via inhibition of ROS production. J Neurosci Res $\mathbf{8 8}, 428-437$.

[55] Yang Y, Liu X, Long Y, Wang F, Ding JH, Liu SY, Sun YH, Yao HH, Wang H, Wu J, Hu G (2006) Activation of mitochondrial ATP-sensitive potassium channels improves rotenone-related motor and neurochemical alterations in rats. Int J Neuropsychopharmacol 9, 51-61.

[56] Tai KK, Truong DD (2002) Activation of adenosine triphosphate-sensitive potassium channels confers protection against rotenone-induced cell death: therapeutic implications for Parkinson's disease. J Neurosci Res 69, 559-566.

[57] Tai KK, McCrossan ZA, Abbott GW (2003) Activation of mitochondrial ATP-sensitive potassium channels increases cell viability against rotenone-induced cell death. J Neurochem 84, 1193-1200.

[58] Liu X, Wu JY, Zhou F, Sun XL, Yao HH, Yang Y, Ding JH, $\mathrm{Hu}$ G (2006) The regulation of rotenone-induced inflammatory factor production by ATP-sensitive potassium channel expressed in BV-2 cells. Neurosci Lett 394, 131-135.

[59] Kis B, Nagy K, Snipes JA, Rajapakse NC, Horiguchi T, Grover GJ, Busija DW (2004) The mitochondrial K(ATP) channel opener BMS-191095 induces neuronal preconditioning. Neuroreport 15, 345-349.

[60] Gaspar T, Katakam P, Snipes JA, Kis B, Domoki F, Bari F, Busija DW (2008) Delayed neuronal preconditioning by NS1619 is independent of calcium activated potassium channels. J Neurochem 105, 1115-1128.

[61] Mayanagi K, Gaspar T, Katakam PV, Kis B, Busija DW (2007) The mitochondrial K(ATP) channel opener BMS191095 reduces neuronal damage after transient focal cerebral ischemia in rats. $J$ Cereb Blood Flow Metab 27, 348-355.

[62] Babcock DF, Hille B (1998) Mitochondrial oversight of cellular Ca2+ signaling. Curr Opin Neurobiol 8, 398-404.

[63] Rizzuto R, Bernardi P, Pozzan T (2000) Mitochondria as all-round players of the calcium game. J Physiol 529(Pt 1), 37-47.

[64] Nicholls DG (2002) Mitochondrial function and dysfunction in the cell: its relevance to aging and aging-related disease. Int J Biochem Cell Biol 34, 1372-1381.

[65] Hengartner MO (2000) The biochemistry of apoptosis. $\mathrm{Na}$ ture 407, 770-776.

[66] Martinou JC, Green DR (2001) Breaking the mitochondrial barrier. Nat Rev Mol Cell Biol 2, 63-67.

[67] Valko M, Leibfritz D, Moncol J, Cronin MT, Mazur M, Telser $\mathrm{J}$ (2007) Free radicals and antioxidants in normal physiological functions and human disease. Int J Biochem Cell Biol 39, 44-84.

[68] Raina AK, Hochman A, Zhu X, Rottkamp CA, Nunomura A, Siedlak SL, Boux H, Castellani RJ, Perry G, Smith MA (2001) Abortive apoptosis in Alzheimer's disease. Acta Neuropathol (Berl) 101, 305-310.

[69] Perry G, Nunomura A, Lucassen P, Lassmann H, Smith MA (1998) Apoptosis and Alzheimer's disease. Science 282, 1268-1269.

[70] Zhu X, Raina AK, Perry G, Smith MA (2006) Apoptosis in Alzheimer disease: a mathematical improbability. Curr Alzheimer Res 3, 393-396.

[71] Dirnagl U, Iadecola C, Moskowitz MA (1999) Pathobiology of ischaemic stroke: an integrated view. Trends Neurosci 22, 391-397. 
[72] Fiskum G (2000) Mitochondrial participation in ischemic and traumatic neural cell death. $J$ Neurotrauma 17, 843-855.

[73] Liou AK, Clark RS, Henshall DC, Yin XM, Chen J (2003) To die or not to die for neurons in ischemia, traumatic brain injury and epilepsy: a review on the stress-activated signaling pathways and apoptotic pathways. Prog Neurobiol 69, 103142.

[74] Lo EH, Dalkara T, Moskowitz MA (2003) Mechanisms, challenges and opportunities in stroke. Nat Rev Neurosci 4, 399415.

[75] Soane L, Kahraman S, Kristian T, Fiskum G (2007) Mechanisms of impaired mitochondrial energy metabolism in acute and chronic neurodegenerative disorders. J Neurosci Res $\mathbf{8 5}$, 3407-3415.

[76] Tsujimoto Y, Shimizu S (2007) Role of the mitochondrial membrane permeability transition in cell death. Apoptosis 12, 835-840.

[77] Schinzel AC, Takeuchi O, Huang Z, Fisher JK, Zhou Z, Rubens J, Hetz C, Danial NN, Moskowitz MA, Korsmeyer SJ (2005) Cyclophilin D is a component of mitochondrial permeability transition and mediates neuronal cell death after focal cerebral ischemia. Proc Natl Acad Sci U SA 102, 1200512010.

[78] Moreira PI, Santos MS, Moreno A, Oliveira C (2001) Amyloid beta-peptide promotes permeability transition pore in brain mitochondria. Biosci Rep 21, 789-800.

[79] Moreira PI, Santos MS, Moreno A, Rego AC, Oliveira C (2002) Effect of amyloid beta-peptide on permeability transition pore: a comparative study. J Neurosci Res 69, 257-267.

[80] Du H, Guo L, Fang F, Chen D, Sosunov AA, McKhann GM, Yan Y, Wang C, Zhang H, Molkentin JD, Gunn-Moore FJ, Vonsattel JP, Arancio O, Chen JX, Yan SD (2008) Cyclophilin $\mathrm{D}$ deficiency attenuates mitochondrial and neuronal perturbation and ameliorates learning and memory in Alzheimer's disease. Nat Med 14, 1097-1105.

[81] Hsu LJ, Sagara Y, Arroyo A, Rockenstein E, Sisk A, Mallory M, Wong J, Takenouchi T, Hashimoto M, Masliah E (2000) alpha-synuclein promotes mitochondrial deficit and oxidative stress. Am J Pathol 157, 401-410.

[82] Song DD, Shults CW, Sisk A, Rockenstein E, Masliah E (2004) Enhanced substantia nigra mitochondrial pathology in human alpha-synuclein transgenic mice after treatment with MPTP. Exp Neurol 186, 158-172.

[83] Hausenloy DJ, Maddock HL, Baxter GF, Yellon DM (2002) Inhibiting mitochondrial permeability transition pore opening: a new paradigm for myocardial preconditioning? Cardiovasc Res 55, 534-543.

[84] Javadov SA, Clarke S, Das M, Griffiths EJ, Lim KH, Halestrap AP (2003) Ischaemic preconditioning inhibits opening of mitochondrial permeability transition pores in the reperfused rat heart. J Physiol 549, 513-524.

[85] Halestrap AP, Clarke SJ, Khaliulin I (2007) The role of mitochondria in protection of the heart by preconditioning. Biochim Biophys Acta 1767, 1007-1031.

[86] Shiva S, Sack MN, Greer JJ, Duranski M, Ringwood LA, Burwell L, Wang X, MacArthur PH, Shoja A, Raghavachari N, Calvert JW, Brookes PS, Lefer DJ, Gladwin MT (2007) Nitrite augments tolerance to ischemia/reperfusion injury via the modulation of mitochondrial electron transfer. J Exp Med 204, 2089-2102.

[87] Zhao H, Sapolsky RM, Steinberg GK (2006) Phosphoinositide-3-kinase/akt survival signal pathways are implicated in neuronal survival after stroke. Mol Neurobiol 34, 249-270.
[88] Wu L, Shen F, Lin L, Zhang X, Bruce IC, Xia Q (2006) The neuroprotection conferred by activating the mitochondrial ATP-sensitive $\mathrm{K}+$ channel is mediated by inhibiting the mitochondrial permeability transition pore. Neurosci Lett $\mathbf{4 0 2}$, 184-189.

[89] Perez-Pinzon MA (2004) Neuroprotective effects of ischemic preconditioning in brain mitochondria following cerebral ischemia. J Bioenerg ] Biomembr 36, 323-327.

[90] Dave KR, DeFazio RA, Raval AP, Torraco A, Saul I, Barrientos A, Perez-Pinzon MA (2008) Ischemic preconditioning targets the respiration of synaptic mitochondria via protein kinase C epsilon. J Neurosci 28, 4172-4182.

[91] Iijima T, Tanaka K, Matsubara S, Kawakami H, Mishima T, Suga K, Akagawa K, Iwao Y (2008) Calcium loading capacity and morphological changes in mitochondria in an ischemic preconditioned model. Neurosci Lett 448, 268-272.

[92] Sack MN (2006) Mitochondrial depolarization and the role of uncoupling proteins in ischemia tolerance. Cardiovasc Res 72, 210-219.

[93] Kim-Han JS, Dugan LL (2005) Mitochondrial uncoupling proteins in the central nervous system. Antioxid Redox Signal 7, 1173-1181.

[94] Duval C, Negre-Salvayre A, Dogilo A, Salvayre R, Penicaud L, Casteilla L (2002) Increased reactive oxygen species production with antisense oligonucleotides directed against uncoupling protein 2 in murine endothelial cells. Biochem Cell Biol 80, 757-764.

[95] Brand MD, Esteves TC (2005) Physiological functions of the mitochondrial uncoupling proteins UCP2 and UCP3. Cell Metab 2, 85-93.

[96] Mattiasson G, Shamloo M, Gido G, Mathi K, Tomasevic G, Yi S, Warden CH, Castilho RF, Melcher T, Gonzalez-Zulueta M, Nikolich K, Wieloch T (2003) Uncoupling protein-2 prevents neuronal death and diminishes brain dysfunction after stroke and brain trauma. Nat Med 9, 1062-1068.

[97] Diano S, Matthews RT, Patrylo P, Yang L, Beal MF, Barnstable CJ, Horvath TL (2003) Uncoupling protein 2 prevents neuronal death including that occurring during seizures: a mechanism for preconditioning. Endocrinology 144, 50145021

[98] Liu Y, Chen L, Xu X, Vicaut E, Sercombe R (2009) Both ischemic preconditioning and ghrelin administration protect hippocampus from ischemia/reperfusion and upregulate uncoupling protein-2. BMC Physiol 9, 17.

[99] Busquets S, Alvarez B, Van Royen M, Figueras MT, LopezSoriano FJ, Argiles JM (2001) Increased uncoupling protein2 gene expression in brain of lipopolysaccharide-injected mice: role of tumour necrosis factor-alpha? Biochim Biophys Acta 1499, 249-256.

[100] Echtay KS, Brand MD (2007) 4-hydroxy-2-nonenal and uncoupling proteins: an approach for regulation of mitochondrial ROS production. Redox Rep 12, 26-29.

[101] Della-Morte D, Dave KR, DeFazio RA, Bao YC, Raval AP, Perez-Pinzon MA (2009) Resveratrol pretreatment protects rat brain from cerebral ischemic damage via a sirtuin 1uncoupling protein 2 pathway. Neuroscience 159, 993-1002.

[102] Nunomura A, Honda K, Takeda A, Hirai K, Zhu X, Smith MA, Perry G (2006) Oxidative damage to RNA in neurodegenerative diseases. J Biomed Biotechnol 2006, 82323.

[103] Hirai K, Hayashi T, Chan PH, Zeng J, Yang GY, Basus VJ, James TL, Litt L (2004) PI3K inhibition in neonatal rat brain slices during and after hypoxia reduces phospho-Akt and increases cytosolic cytochrome c and apoptosis. Brain Res Mol Brain Res 124, 51-61. 
[104] Murakami K, Kondo T, Kawase M, Li Y, Sato S, Chen SF, Chan PH (1998) Mitochondrial susceptibility to oxidative stress exacerbates cerebral infarction that follows permanent focal cerebral ischemia in mutant mice with manganese superoxide dismutase deficiency. $J$ Neurosci 18, 205-213.

[105] Noshita N, Sugawara T, Fujimura M, Morita-Fujimura Y, Chan PH (2001) Manganese Superoxide Dismutase Affects Cytochrome c Release and Caspase-9 Activation After Transient Focal Cerebral Ischemia in Mice. J Cereb Blood Flow Metab 21, 557-567.

[106] Scorziello A, Santillo M, Adornetto A, Dell'aversano C, Sirabella R, Damiano S, Canzoniero LM, Renzo GF, Annunziato L (2007) NO-induced neuroprotection in ischemic preconditioning stimulates mitochondrial Mn-SOD activity and expression via Ras/ERK1/2 pathway. J Neurochem 103, 14721480.

[107] Correia SC, Moreira PI (2010) Hypoxia-inducible factor 1: a new hope to counteract neurodegeneration? J Neurochem 112, 1-12.

[108] Baranova O, Miranda LF, Pichiule P, Dragatsis I, Johnson RS, Chavez JC (2007) Neuron-specific inactivation of the hypoxia inducible factor 1 alpha increases brain injury in a mouse model of transient focal cerebral ischemia. J Neurosci 27, 6320-6332.

[109] Soucek T, Cumming R, Dargusch R, Maher P, Schubert D (2003) The regulation of glucose metabolism by HIF-1 mediates a neuroprotective response to amyloid beta peptide. Neuron 39, 43-56.

[110] Lee DW, Rajagopalan S, Siddiq A, Gwiazda R, Yang L, Beal MF, Ratan RR, Andersen JK (2009) Inhibition of prolyl hydroxylase protects against 1-methyl-4-phenyl-1,2,3,6tetrahydropyridine-induced neurotoxicity: model for the potential involvement of the hypoxia-inducible factor pathway in Parkinson disease. J Biol Chem 284, 29065-29076.

[111] Bell EL, Klimova TA, Eisenbart J, Moraes CT, Murphy MP, Budinger GR, Chandel NS (2007) The Qo site of the mitochondrial complex III is required for the transduction of hypoxic signaling via reactive oxygen species production. $J$ Cell Biol 177, 1029-1036.

[112] Brunelle JK, Bell EL, Quesada NM, Vercauteren K, Tiranti V, Zeviani M, Scarpulla RC, Chandel NS (2005) Oxygen sensing requires mitochondrial ROS but not oxidative phosphorylation. Cell Metab 1, 409-414.

[113] Guzy RD, Hoyos B, Robin E, Chen H, Liu L, Mansfield KD, Simon MC, Hammerling U, Schumacker PT (2005) Mitochondrial complex III is required for hypoxia-induced ROS production and cellular oxygen sensing. Cell Metab 1, 401-408.

[114] Chandel NS, Maltepe E, Goldwasser E, Mathieu CE, Simon MC, Schumacker PT (1998) Mitochondrial reactive oxygen species trigger hypoxia-induced transcription. Proc Natl Acad Sci U S A 95, 11715-11720.

[115] Chandel NS, McClintock DS, Feliciano CE, Wood TM, Melendez JA, Rodriguez AM, Schumacker PT (2000) Reactive oxygen species generated at mitochondrial complex III stabilize hypoxia-inducible factor-1alpha during hypoxia: a mechanism of O2 sensing. J Biol Chem 275, 25130-25138.

[116] Mansfield KD, Guzy RD, Pan Y, Young RM, Cash TP, Schumacker PT, Simon MC (2005) Mitochondrial dysfunction resulting from loss of cytochrome c impairs cellular oxygen sensing and hypoxic HIF-alpha activation. Cell Metab 1, 393-399.

[117] Liu J, Narasimhan P, Yu F, Chan PH (2005) Neuroprotection by hypoxic preconditioning involves oxidative stressmediated expression of hypoxia-inducible factor and erythropoietin. Stroke 36, 1264-1269.

[118] Chang S, Jiang X, Zhao C, Lee C, Ferriero DM (2008) Exogenous low dose hydrogen peroxide increases hypoxiainducible factor-1alpha protein expression and induces preconditioning protection against ischemia in primary cortical neurons. Neurosci Lett 441, 134-138. 